\title{
The stability likelihood of an international climate agreement
}

\author{
Rob Dellink · Michael Finus · Niels Olieman
}

Received: 15 February 2006 / Accepted: 19 April 2007 / Published online: 24 May 2007

(C) Springer Science+Business Media B.V. 2007

\begin{abstract}
Results derived from empirical analyses on the stability of climate coalitions are usually very sensitive to the large uncertainties associated with the benefits and costs of climate policies. This paper provides the methodology of Stability Likelihood (SL) that links uncertainties about benefits and costs of climate change to the stability of coalitions. We show that the concept of SL improves upon the robustness and interpretation of stability analyses. Moreover, our numerical application qualifies conclusions from a recent strand of literature based on stylised models with ex-ante symmetric players that learning has a negative impact on the success of coalition formation in context of uncertainty.
\end{abstract}

Keywords Climate change modelling · International environmental agreements · Non-cooperative game theory $\cdot$ Uncertainty

JEL Classification $\mathrm{C} 79 \cdot \mathrm{H} 87 \cdot \mathrm{Q} 54$

\footnotetext{
R. Dellink ( $\varangle)$

Environmental Economics and Natural Resources Group, Wageningen University, Hollandseweg 1, Wageningen $6706 \mathrm{KN}$, The Netherlands e-mail: rob.dellink@wur.nl

R. Dellink Institute for Environmental Studies, Vrije Universiteit Amsterdam, Amsterdam, The Netherlands
}

M. Finus

Institute of Economic Theory, Department of Economics, University of Hagen, Hagen, The Netherlands

N. Olieman

Operations Research and Logistics Group, Wageningen University, Wageningen, The Netherlands

N. Olieman

Risk Model Validation and Methodologies Department, Rabobank Netherlands, Rabobank,

The Netherlands 


\section{Introduction}

There are many obstacles that prevent the formation of effective international environmental agreements (IEAs). Two of the most important obstacles are free-riding and uncertainty.

First, IEAs aim at providing a public good and therefore countries face free-rider incentives. Typically it is beneficial for a country when other regions increase their abatement efforts. This free-riding problem has been studied extensively in theoretical models, as for instance in Hoel (1992), Carraro and Siniscalco (1993) and Barrett (1994) and in empirical climate models, as for instance in Bosello et al. (2003), Botteon and Carraro (1997), Tol (2001), Eyckmans and Finus (2006), and Finus et al. (2006). A main conclusion of this literature is that stable coalitions improve only marginally upon the non-cooperative outcome because either stable coalitions are small or the global abatement level that can be sustained in larger coalitions is very low. However, regardless of the specific model, all of these papers determine stable coalitions in a deterministic setting.

Second, the uncertainties surrounding the future impacts of climate change as well as abatement costs are large. In particular, the benefits from abatement that arise in the distant future are highly uncertain, but also future abatement costs are not fully known. These issues are highlighted for instance in Roughgarden and Schneider (1999) and Tol (2002, 2005). Depending on the model specification and assumptions, uncertainty and learning may either call for laxer environmental standards today or imply that countries follow the precautionary principle by increasing their short-term abatement efforts (Kolstad 1996a, b; Ulph and Maddison 1997; Ulph and Ulph 1997). However, regardless of how uncertainty and learning is captured in these papers and what this means for optimal abatement strategies, success can only be evaluated if free-rider incentives are also included in the analysis. This implies that models with a single global decision-maker cannot provide full insight into the regional impacts of uncertainty and learning. This drawback is common to most integrated assessment models that are used to analyse optimal abatement strategies, including for instance DICE/RICE (Nordhaus and Boyer 2000), MERGE (Manne et al. 1995) and EPPA (Babiker et al. 2001). This also applies to some extent to models with two countries that compare non-cooperative with cooperative behaviour and hence coalition formation is not really an issue in these models (e.g. Ulph and Maddison 1997; Ulph and Ulph 1997).

Recently, some papers have appeared that combine coalition formation with uncertainty and learning (Na and Shin 1998; Ulph 2004; Kolstad and Ulph 2006; Kolstad 2007). They assume uncertainty about parameter values of the payoff function where probability distribution functions are known to all countries. In the context of coalition formation, in which countries choose their membership in the first stage and their abatement strategies in the second stage, this allows to distinguish three cases according to Kolstad and Ulph (2006) and Kolstad (2007): (1) Uncertainty is resolved before the first stage. This corresponds to the case of full learning. (2) Uncertainty is resolved after the first stage but before the second stage. This corresponds to the case of partial learning. (3) Uncertainty is not resolved. This is the case with no learning. In cases 1 and 2 where there is learning, it takes the form of perfect learning, i.e. all players learn the true values of all uncertain parameters.

All these papers are stylized models with ex-ante identical players and mostly come to the conclusion that learning has a negative impact on the success of coalition formation. $\mathrm{Na}$ and Shin (1998) compare case 2 and 3, but their model is essentially static (flow pollutant) and restricted to only three countries. The first restriction is removed in Ulph (2004), who compares all three cases and considers a two period model with a stock pollutant. Due to this complication, results are based on simulations and conclusions are not always clear-cut. Moreover, he assumes that countries have only two abatement strategies (no abatement versus 
full abatement), the only uncertainty concerns the benefits from global abatement, with only two states (low and high benefits) and uncertainty is correlated between players. This means that in the case of learning all countries are also ex-post identical; either all countries are low or high benefit countries. These assumptions are also made in Kolstad (2007). Because of the assumption of a flow pollutant, he unambiguously shows that when comparing case 1 and 3, learning increases the size of a stable IEA but has a negative impact on global welfare, as proven in Kolstad and Ulph (2006). Case 2 is ambiguous; learning may have a positive or negative impact on participation and welfare. Finally, in the case of uncorrelated uncertainty, Kolstad and Ulph (2006) confirm the negative impact of learning, but again have to resort to simulation, despite the assumption that all countries are ex-ante identical and that there are only two states in the world.

Because of the difficulties of deriving analytical results even in a simple model, we consider uncertainty, learning and coalition formation based on an empirical climate model with twelve heterogeneous world regions. In the first stage, regions can only choose between becoming a signatory or to remain an outsider as assumed in the papers above. However, in the second stage, regions can choose from a continuum of abatement strategies, while almost all model parameters are assumed to be uncertain with (uncorrelated) probability distribution functions. We restrict ourselves to the analysis of cases 1 and 3, namely no and full resolution of uncertainty. Case 1 is relatively straightforward. Because we assume that utility is linear in payoffs as in Kolstad and Ulph (2006), we can also apply the certainty equivalence principle. That is, the case of no resolution of uncertainty is identical to the deterministic case if the mean or expected value of a parameter corresponds to the value in the deterministic case. Together with case 3, which is the focus of this analysis, case 1 allows for a direct comparison with the conclusions derived in Kolstad and Ulph (2006). Case 3 implies that a coalition cannot be called stable or not stable any longer (based on certain payoffs in the deterministic case or expected payoffs in the case of no resolution of uncertainty). For this, we introduce our concept of Stability Likelihood (SL), which determines the likelihood that a coalition structure is stable. Compared to Kolstad and Ulph (2006) and the other papers above, we find that learning does not always have a negative impact on the success of coalition formation. Moreover, we show that the concept of SL has advantages over a deterministic analysis. Firstly, in a deterministic setting, coalitions can only be stable or unstable. This may imply in some cases that small perturbations of parameters are sufficient to change the set of stable coalitions, invalidating conclusions. Secondly, in a deterministic model, uncertainty of parameter values can only be indirectly accounted for through sensitivity analyses where each analysis is subject to the first problem mentioned above. Hence, the concept of SL can be interpreted as a more sophisticated sensitivity analysis than is traditionally done in the context of coalition formation with empirical data, as for instance in Eyckmans and Finus (2006) and Finus et al. (2006).

In the following, we present our model of coalition formation and introduce the concept of SL in Sect. 2. Section 3 discusses the calibration of the model, including the distribution functions used for the uncertain model parameters. Section 4 presents and discusses result of our stability analysis. Section 5 concludes.

\section{The model of coalition formation}

Consider a set of $\mathrm{N}$ heterogeneous players, each representing a region of the world. In the first stage, regions decide whether to become a member of IEA or to remain an outsider. Announcement $c_{i}=1$ means "Region $i$ joins the coalition" and announcement $c_{i}=0$ 
"Region $i$ remains an outsider"; a coalition structure $c$ is described by announcement vector $c=\left(c_{1}, \ldots, c_{N}\right)$. The set of players that announce 1 are coalition members and is denoted as $k=\left\{i \mid c_{i}=1, \forall i=1, \ldots, \mathrm{N}\right\}$. Thus, in this simple setting, a coalition structure is defined by coalition $k$. Hence, we can use the term coalition structure and coalition interchangeably. Note that there are $2^{N}$ announcement vectors, but essentially there are only $2^{N}-N$ coalition structures. The reason is that regardless whether all regions announce $c_{i}=0$ or only one region announces $c_{i}=1$ and all other announce $c_{i}=0$, this will result in the "All-Singletons Coalition Structure".

In the second stage, regions choose their abatement levels. This leads to abatement vector $q=\left(q_{1}, \ldots, q_{\mathrm{N}}\right)$. The payoff of an individual region $i, \pi_{i}(q, \mathrm{~b})$ depends on abatement vector $q$ (and hence on the strategy of all regions, due to the public good nature of abatement) and on a vector of model parameters $b$.

We solve the game backwards assuming that strategies in each stage must form a Nash equilibrium. For the second stage, this entails that abatement strategies form a Nash equilibrium between coalition $k$ and the remaining non-signatories. That is,

$$
\begin{gathered}
\sum_{i \in k} \pi_{i}\left(q_{k}^{*}, q_{-k}^{*}, \mathrm{~b}\right) \geq \sum_{i \in k} \pi_{i}\left(q_{k}, q_{-k}^{*}, \mathrm{~b}\right) \forall q_{k} \text { and } \\
\pi_{i}\left(q_{k}^{*}, q_{i}^{*}, q_{-i}^{*}, \mathrm{~b}\right) \geq \pi_{i}\left(q_{k}^{*}, q_{i}, q_{-i}^{*}, \mathrm{~b}\right) \forall q_{i}
\end{gathered}
$$

where $q_{k}$ is the abatement strategy vector of coalition $k, q_{-k}$ the vector of all regions not belonging to $k, q_{i}$ the strategy of non-signatory $i$, and $q_{-i}$ the strategy vector of all other non-signatories except $i$. An asterisk denotes equilibrium strategies. Computationally, this implies that non-signatories $(i \notin k)$ that announced $c_{i}=0$ will choose their abatement strategies so as to maximize their individual payoff $\pi_{i}(q, \mathrm{~b})$, whereas all signatories $(i \in k)$ that announced $c_{i}=1$ jointly maximize the aggregate payoff of their coalition $\sum_{i \in k} \pi_{i}(q, \mathrm{~b})$, taking the abatement strategies of all other regions as given. Strategically, this means that the behaviour of non-signatories towards all other regions is selfish and non-cooperative; signatories' behaviour is cooperative towards their fellow members, but non-cooperative towards outsiders. Economically, this means strategies are group (but not globally) efficient within coalition $k$. Hence, the equilibrium economic strategy vector $q^{*}$ corresponds to the classical "social or global optimum" if coalition $k$ comprises all countries, i.e. the grand coalition forms, and corresponds to the classical "Nash equilibrium" if coalition $k$ comprises only one member or is empty. Thus, any inefficiency stems from the fact that $k$ is not the grand coalition.

Since in the context of our empirical model the equilibrium abatement vector $q^{*}$ is unique for every coalition structure $c$ and a given vector of parameters $b$ (see the proof in Olieman and Hendrix 2006), there is a unique vector of equilibrium payoffs for every coalition structure $c$ :

$$
v_{i}(c, \mathrm{~b}) \equiv \pi_{i}\left(q^{*}(c), \mathrm{b}\right)
$$

We now turn to the first stage. Also in the first stage, strategies form a Nash equilibrium. That is, no signatory that announced $c_{i}=1$ should have an incentive to change its announcement to $\tilde{c}_{i}=0$ (internal stability) and no non-signatory that announced $c_{i}=0$ should want to announce $\tilde{c}_{i}=1$ (external stability), given the announcement of other players $c_{-i}$. For our purposes, this condition can be summarised compactly by the payoff stability function $f(c, \mathrm{~b})$, which assigns the value 1 to a stable announcement vector (i.e. stable coalition) and the value 0 to an unstable announcement vector (i.e. unstable coalition): 


$$
f(c, \mathrm{~b})= \begin{cases}1 & \text { if }\left(v_{i}\left(c_{i}, c_{-i}, \mathrm{~b}\right)-v_{i}\left(\tilde{c}_{i}, c_{-i}, \mathrm{~b}\right) \geq 0\right) \text { for } \tilde{c}_{i}=1-c_{i} \text { and for all } \\ & i=1, \ldots, \mathrm{N} \\ 0 \quad & \text { else }\end{cases}
$$

The function $f(c, \mathrm{~b})$ will take on the value 1 if for all regions the payoff from announcement $c$ is higher than, or equal to, the payoff associated with alternative announcements $\tilde{c}$. These alternatives are constructed by changing the announcement of one player at a time. It is worth noting that for any given set of parameters $b$, this function allows for either a unique stable coalition, multiple stable coalitions or no non-trivial stable coalition.

In a deterministic model, the vector of parameters b may be based on estimates but is treated as given. In contrast, in a stochastic model the deterministic vector of parameters $b$ is replaced by the stochastic (vector) variable $\boldsymbol{b}$ which is characterised by probability space $(\mathrm{B}, B, \operatorname{Pr})$ and probability density function $g(b)$. In the case of no resolution of uncertainty, the decision on membership in the first stage will be based on expected payoffs using the mean values of $\boldsymbol{b}$. If the vector of mean values of $\boldsymbol{b}$ is $b$, this corresponds to the deterministic setting. However, in the case of full resolution, decisions are based on the stochastic variable $\boldsymbol{b}$ and as function $f(c, \boldsymbol{b})$ becomes a Bernoulli variable, we can assign a likelihood to the event $f(c, b)=1$, i.e. to a stable coalition.

The SL of coalition structure $c$ is therefore defined as $\mathrm{SL} \equiv \operatorname{Pr}\{f(c, \boldsymbol{b})=1\}$, which equals $\int_{\mathrm{B}} f(c, b) \cdot g(b) \mathrm{d} b$. Assuming that $f($.$) is a correct representation of reality, we can$ interpret SL as the probability that coalition structure $c$ is stable.

The heterogeneity of players with payoff functions based on the empirical model STACO (see Sect. 3), requires us to resort to numerical calculations for the SL of various coalitions. ${ }^{1}$ The SL is calculated using a Monte Carlo sampling technique: we generate M samples $b_{\mathrm{m}}$ from $\boldsymbol{b}$; based on these samples we can estimate the SL with $\widehat{S L}=\frac{1}{\mathrm{M}} \sum_{\mathrm{m}=1}^{\mathrm{M}} f\left(c, b_{\mathrm{m}}\right)$ that has an estimated variance of $\frac{1}{\mathrm{M}-1}(\widehat{S L}(1-\widehat{S L}))$.

A more detailed discussion of the SL concept and computation methods can be found in Olieman and Hendrix (2006).

\section{Calibration of the model}

\subsection{Introduction}

In this section, the calibration of the empirical model, called STAbility of COalitions (STA$\mathrm{CO}$ ) is described. For more detailed information on the model and calibration procedure, see Dellink et al. (2004) and Finus et al. (2006). The model comprises benefit and cost functions of twelve world regions: USA (USA), Japan (JPN), European Union (EEC), other OECD countries (OOE), Eastern European countries (EET), former Soviet Union (FSU), energy exporting countries (EEX), China (CHN), India (IND), dynamic Asian economies (DAE), Brazil (BRA) and "rest of the world" (ROW). The philosophy behind the construction of the model comprises two items. First, the model must be simple enough to allow for sufficient samples to be calculated within reasonable time. ${ }^{2}$ Second, the model should reflect important results and features of integrated assessment models in terms of overall magnitudes of global

\footnotetext{
1 We are not aware of any paper that provides analytical solutions of stable coalitions in the context of heterogeneous players even in the absence of uncertainty.

2 We need around 40,000 samples to get sufficient accuracy in the estimates of SL. This implies around 2 billion calculations of optimal regional abatement and payoff levels (40,000 times 12 regions times 4096 membership announcement vectors).
} 
emissions and concentration, abatement costs from regional abatement and benefits from global abatement over some time period. Therefore, the model focuses on carbon dioxide, but the exogenous level of other greenhouse gases is included in the calibration of the benefit function ( $c f$. Nordhaus 1994). The analysis is based on the net present value of a stream of net benefits starting in 2010 and covering a time period of 100 years in order to capture the long-run effects of global warming. They are computed for every possible coalition structure and then stability is computed according to the procedure explained in Sect. 2. The price for this complexity (see footnote 2) is that we assume constant abatement strategies (cf. Sect. 3.2), rendering the model essentially static as in $\mathrm{Na}$ and Shin (1998), Kolstad and Ulph (2006) and Kolstad (2007). Therefore, numerical results should be interpreted with caution. However, this allows for a direct comparision with the papers mentioned above about the role of learning. Moreover, we believe that our simulations illustrate the usefulness of SL as an indicator, as we include the best available information on the probability density functions of the model parameters.

\subsection{Elements of the empirical model}

The payoff function of region $i$ is given by:

$$
\pi_{i}=\sum_{t=1}^{T}(1+r)^{-t}\left(B_{i t}\left(q_{t}\right)-A C_{i t}\left(q_{i t}\right)\right)
$$

where $T$ denotes the time horizon, $t=2011, \ldots, 2110 ; r$ is the discount rate; $B_{\text {it }}$ are benefits from global abatement $\left(q_{t}=\sum_{i=1}^{N} q_{\mathrm{it}}\right)$; and $A C_{\mathrm{it}}$ are abatement costs from regional abatement $q_{\text {it }}$.

The payoff function is calculated as the net present value of a stream of net benefits from abatement between 2010 and 2110 and thus reflects discounted avoided damages minus discounted abatement costs. Regional abatement costs are a function of the level of individual abatement by region $i$, while regional benefits depend on global abatement efforts.

Assuming constant abatement strategies $\left(q_{\text {it }}=q_{i} / 100\right)$, benefits in year $t$ can be expressed as a function of global abatement over the entire period. Furthermore, we consider that the stock of $\mathrm{CO}_{2}$ can be approximated by a linear function of emissions and that damages are linear in the stock of $\mathrm{CO}_{2} \cdot{ }^{3}$ It follows that annual global benefits from reduced emissions are also linear in the level of abatement:

$$
B_{t}(q)=\varphi_{t} \cdot q
$$

where $\varphi_{t}$ denotes marginal benefits in period $t$ from total abatement over the entire period. This parameter also includes the effects of limited retention of GHGs in the atmosphere and the decay of the stock of GHGs over time. As benefits in period $t$ result from the stream of abatement in all periods until $t$, these marginal benefits are increasing over time.

Discounted global or total benefits, $T B(q)$ can then be expressed as

$$
T B(q)=\gamma \cdot q
$$

where $\gamma$ represents discounted marginal benefits in $\$ /$ ton carbon equivalents (tC) and is calculated as

$$
\gamma=\sum_{t=2011}^{2110}(1+r)^{-t} \cdot \varphi_{t} .
$$

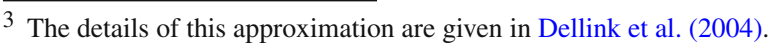


Regional discounted benefits are assumed to be a share of discounted global benefits from abatement:

$$
T B_{i}(q)=s_{i} \cdot T B(q)=s_{i} \cdot \gamma \cdot q
$$

where $s_{i}$ is the share of global benefits for region $i$ and $\sum_{i=1}^{N} s_{\mathrm{i}}=1$.

For the specification of the abatement cost functions, estimates of the EPPA model are used (Ellerman and Decaux 1998). It assumes an annual abatement cost function of region $i$ of the following form:

$$
A C_{i t}\left(q_{i t}\right)=\frac{1}{3} \cdot \alpha_{i} \cdot\left(q_{i t}\right)^{3}+\frac{1}{2} \cdot \beta_{i} \cdot\left(q_{i t}\right)^{2}
$$

with $\alpha_{i}$ and $\beta_{i}$ regional cost parameters. Total abatement cost of region $i, T A C_{i}\left(q_{i}\right)$, is the sum of annual abatement cost over the entire time horizon. Assuming constant strategies and a constant discount rate, as in the case of benefits, the total abatement cost function becomes

$$
T A C_{i}\left(q_{i}\right)=\rho \cdot\left(\frac{1}{3} \cdot \alpha_{i} \cdot\left(q_{i}\right)^{3}+\frac{1}{2} \cdot \beta_{i} \cdot\left(q_{i}\right)^{2}\right)
$$

with

$$
\rho=\sum_{t=2011}^{2110}(1+r)^{-t}
$$

Taken together, the payoff function of region $i$ can be written as: ${ }^{4}$

$$
\pi_{i}=T B_{i}(q)-T A C_{i}\left(q_{i}\right) .
$$

Generally, all model parameters are uncertain. However, we have insufficient information to fully estimate the probability density functions of all parameters at a regional level. A more advanced meta-analysis of published and unpublished estimates would require a study of its own and therefore is beyond the scope of the current paper. Hence, we consider only uncertainty of the benefit and cost parameters $\gamma, s_{i}, \alpha_{i}$ and $\beta_{i}$. Other parameters, such as emissions in 2010, the decay rate of greenhouse gases and the discount rate are assumed to be known with certainty. Calibration of emissions and concentrations is based on the widely known DICE-model by Nordhaus (1994).

The discount rate $r$ is set at $2 \%$ per year. This is in line with Weitzman $(1998,2001)$ who suggests that in the case of climate change long-terms effects should be discounted with a low discount rate and suggests that $2 \%$ is appropriate for the "medium future". In Sect. 4.3, we also consider the possibility of a higher discount rate, though this done indirectly by lowering the mean value of the global benefit parameter $\gamma$. We want to stress that the discount rate only affects the aggregation of costs and benefits over time, as marginal benefits are

\footnotetext{
${ }^{4}$ This means that we base our stability analysis on the net present value of benefits and abatement costs (i.e. discounted payoffs). The assumption that the abatement paths are constant over time simplifies the calculations, but is not essential. The nature of our analysis requires only that the overall magnitude of concentrations and emissions mimics that of more elaborate integrated assessment models (because decisions whether to join a coalition are based on discounted payoffs). The exact shape of the equilibrium emission or abatement paths are not important for our analysis. A similar stability analysis in a deterministic setting with dynamic equilibrium abatement paths, as reported in Nagashima et al. (2006), reveals that the impact of our simplifying assumption is limited: while levels of payoffs are somewhat affected, the stability of coalitions is robust in this respect.
} 
Table 1 Characteristics of the 2-sided exponential distribution function of the global benefit parameter $\gamma$

\begin{tabular}{ll}
\hline & Value \\
\hline $5 \%$ Density & $-9 \$ / \mathrm{tC}$ \\
Mode & $5 \$ / \mathrm{tC}$ \\
Density at mode & $13 \%$ \\
$95 \%$ density & $245 \$ / \mathrm{tC}$ \\
Mean & $77 \$ / \mathrm{tC}$ \\
\hline
\end{tabular}

constant (though uncertain). Note also that our assumption of a constant (money) discount rate is consistent with a low, but positive, pure rate of time preference. ${ }^{5}$

\subsection{Global benefit function}

The distribution function of the global benefit parameter $\gamma$ is based on a recent study by Tol (2005). The probability density function of peer-reviewed studies as presented by Tol can be closely mimicked by a 2-sided exponential function. This function is described by four pieces of information: (i) the 5 percentile point; (ii) the value where the two sides of the exponential function are separated (assuming this is above the 5 percentile point); (iii) the cumulative probability density at this separation value; and (iv) the 95 percentile point (assuming this is above the separation value). The first piece of information is given by the value that corresponds to a cumulative probability of $5 \%$; this value equals $-9 \$ / \mathrm{tC}$, implying a strictly positive probability that benefits from abatement are negative. The point of separation between both sides of the function is given by the mode and equals $5 \$ / \mathrm{tC}$; the associated cumulative probability density is $13 \%$. The point on the right side of the function is given by the $95 \%$ cumulative probability density and equals $245 \$ / \mathrm{tC}$. The mean value of this function is $77 \$ / \mathrm{tC}$. These numbers are summarised in Table 1 and the corresponding histogram of all drawn samples is shown in Appendix I. This distribution function implies that there is a probability of around $9 \%$ that the benefits from global abatement are zero or negative. In this case, optimal abatement is zero, and regions are indifferent between no, partial and full cooperation.

\subsection{Regional benefit shares}

The distribution function of regional benefit shares $\left(s_{i}\right)$ is based on insights from a study by Tol (2002). However, this source does not provide sufficient information on the functional form of the distribution function of these shares. Therefore, we opt for a gamma distribution that can handle the lower bound of the shares such that no region receives a negative share of the benefits. Moreover, as the shares can vary between zero and one and the mean value is typically close to zero, the distribution function should be skewed, as this is the case for a gamma distribution. However, the choice of the gamma distribution function will be subject to a sensitivity analysis in Sect. 4.4.

The mean values used for the regional shares are the values reported in the deterministic setting of the STACO model, which are in turn based on Fankhauser (1995) and Tol (1997). Standard deviations are based on expert judgement, using in particular Tol (2002). Typically,

\footnotetext{
5 Alternatively, we could assume a constant pure rate of time preference of $0.5 \%$ and use the Ramsey rule to derive a declining discount rate; as only net present values matter in our model, these two alternatives are equivalent for our analysis.
} 
Table 2 Characteristics of the gamma distribution function of the regional parameter $s_{i}$ (share of global benefits)

\begin{tabular}{llll}
\hline Region & Lower bound & Mean & Standard deviation \\
\hline USA & 0 & 0.2263 & 0.1414 \\
JPN & 0 & 0.1725 & 0.1078 \\
EEC & 0 & 0.2360 & 0.1475 \\
OOE & 0 & 0.0345 & 0.0216 \\
EET & 0 & 0.0130 & 0.0130 \\
FSU & 0 & 0.0675 & 0.0675 \\
EEX & 0 & 0.0300 & 0.0300 \\
CHN & 0 & 0.0620 & 0.0620 \\
IND & 0 & 0.0500 & 0.1000 \\
DAE & 0 & 0.0249 & 0.0498 \\
BRA & 0 & 0.0153 & 0.0306 \\
ROW & 0 & 0.0680 & 0.1360 \\
\hline
\end{tabular}

standard deviations are of the same order of magnitude as mean values, and are lower for OECD countries than for the other regions. The regional numbers are represented in Table 2. For a better understanding, the corresponding histograms for the USA and China are shown in Appendix I.

After the samples of the regional shares are drawn, all shares are scaled up or down to force the sum of shares to unity. This implies that the regional shares do not strictly follow the gamma distribution and the resulting variance in the shares is smaller than in the original gamma distribution. ${ }^{6}$ Though rescaling is not a necessary condition for the working of the model, the restriction on the sum of shares is enforced to avoid an impact of variations in this parameter on global benefits. The consequences of this assumption will be investigated in a sensitivity analysis in Sect. 4.4

\subsection{Abatement cost functions}

The two regional abatement cost parameters $\left(\alpha_{i}\right.$ and $\left.\beta_{i}\right)$ cannot be assumed to be independent. Typically, empirical studies report only variations in marginal abatement costs without providing information on how the slopes and curvatures of these functions vary. Therefore, we assume the functional form of the abatement cost curves to be given, and vary the level of marginal abatement costs per region in the simulations. This implies that both parameters in the abatement cost functions move simultaneously and in the same direction. ${ }^{7}$

We assume a normal distribution function; the mean is based on the deterministic version of the STACO model, which is in turn based on Ellerman and Decaux (1998). The normal distribution is chosen, as a priori, there seems to be no reason to assume a skewed distribution. The standard deviation of the abatement cost parameters are based on information provided by IPCC (Metz et al. 2001). Due to lack of regional information, the standard deviation is

\footnotetext{
6 More information on the impact of this rescaling on the probability density function can be obtained from the authors upon request.

7 Effectively, we replace equation (6b) by $T A C_{i}\left(q_{i}\right)=\psi_{i} \cdot \rho \cdot\left(\frac{1}{3} \cdot \alpha_{i} \cdot\left(q_{i}\right)^{3}+\frac{1}{2} \cdot \beta_{i} \cdot\left(q_{i}\right)^{2}\right)$, where $\psi_{i}$ is stochastic with mean value 1 and $\alpha_{i}$ and $\beta_{i}$ are deterministic. However, we interpret the model as if the variation occurs in $\alpha_{i}$ and $\beta_{i}$.
} 
Table 3 Characteristics of the normal distribution of the abatement cost parameters $\alpha_{i}$ and $\beta_{i}$

\begin{tabular}{lllll}
\hline Region & $\alpha_{i}$ & & $\beta_{i}$ & \\
\cline { 2 - 3 } & Mean & Standard deviation & Mean & Standard deviation \\
\hline USA & 0.00050 & 0.00006 & 0.00398 & 0.00050 \\
JPN & 0.01550 & 0.00194 & 0.18160 & 0.02270 \\
EEC & 0.00240 & 0.00030 & 0.01503 & 0.00188 \\
OOE & 0.00830 & 0.00104 & 0.00000 & 0.00000 \\
EET & 0.00790 & 0.00198 & 0.00486 & 0.00122 \\
FSU & 0.00230 & 0.00058 & 0.00042 & 0.00011 \\
EEX & 0.00320 & 0.00080 & 0.03029 & 0.00757 \\
CHN & 0.00007 & 0.00002 & 0.00239 & 0.00060 \\
IND & 0.00150 & 0.00038 & 0.00787 & 0.00197 \\
DAE & 0.00470 & 0.00118 & 0.03774 & 0.00944 \\
BRA & 0.56120 & 0.14030 & 0.84974 & 0.21244 \\
ROW & 0.00210 & 0.00053 & 0.00805 & 0.00201
\end{tabular}

calibrated to $12.5 \%$ of the mean for OECD regions and 25\% for non-OECD regions. Hence, the variation in abatement costs is typically much smaller than the variation in benefits for most regions. The key inputs for the normal distribution are shown in Table 3 and for USA and China the corresponding probability density functions are illustrated in Appendix I.

\section{Results}

Using the confidence intervals and distribution functions described above, we calculate the SL of all possible 4084 coalition structures. Results of this simulation are reported and discussed in Sect. 4.1. Section 4.2 identifies, which uncertainties are the main determinants of the SL for selected coalitions using a meta-modelling approach. Section 4.3 investigates an alternative scenario with lower probability of extreme observations for the benefits from abatement, by adopting much stricter bounds on the distribution function of the global benefit parameter. These stricter bounds imply a lower mean value of global benefits. Section 4.4 briefly discusses the results of some sensitivity analyses on the uncertainty of the various parameters and the associated distribution functions. All simulations are carried out with a precision of $95 \%$ on the second digit of SL $\left(\sigma_{S L}=0.0025\right)$, implying that we keep drawing samples until we have sufficient accuracy on SL to present two decimals.

\subsection{Results for the base specification}

Table 4 presents the main results for those coalition structures that have the highest SL and for the Grand Coalition. Note that the stability of the All-Singletons Coalition Structure is $\mathrm{SL}=1$ by definition. This coalition structure can always be supported as an equilibrium if all regions announce $c_{i}=0$. In the All-Singletons Coalition Structure abatement efforts amount to almost $70 \mathrm{GtC}$ per century, or an annual abatement of $5.8 \%$ of global emissions in 2010 , which leads to a discounted payoff of almost 8.8 trillion US\$ over the century. The relatively high abatement level is due to a high value of the global benefit parameter $\gamma$ in the study 
Table 4 Results for selected coalitions (mean values)

\begin{tabular}{lllllc}
\hline Coalition & SL (fraction) & $\begin{array}{l}\text { Strict SL } \\
\text { (fraction) }\end{array}$ & $\begin{array}{l}\text { Total abatement } \\
(\mathrm{GtC})\end{array}$ & $\begin{array}{l}\text { Abatement } \\
(\% \text { of emissions) }\end{array}$ & $\begin{array}{l}\text { Total } \\
\text { payoff (bln \$) }\end{array}$ \\
\hline All-Singletons & 1 & 1 & 69.4 & $5.8 \%$ & 8775 \\
JPN,EEC & 0.24 & 0.15 & 74.5 & $6.2 \%$ & 9251 \\
USA,JPN & 0.15 & 0.06 & 79.1 & $6.6 \%$ & 9663 \\
USA,EEC & 0.14 & 0.05 & 84.7 & $7.1 \%$ & 10090 \\
JPN,BRA & 0.12 & 0.02 & 69.7 & $5.8 \%$ & 8824 \\
JPN,ROW & 0.11 & 0.02 & 76.7 & $6.4 \%$ & 9613 \\
EEC,ROW & 0.11 & 0.01 & 79.2 & $6.6 \%$ & 9835 \\
JPN,IND & 0.10 & 0.01 & 78.0 & $6.5 \%$ & 9773 \\
JPN,FSU & 0.10 & 0.01 & 75.8 & $6.3 \%$ & 9475 \\
EEC,BRA & 0.10 & 0.01 & 70.1 & $5.9 \%$ & 8857 \\
EEC,FSU & 0.10 & 0.01 & 78.4 & $6.6 \%$ & 9699 \\
Grand Coalition & 0.09 & 0 & 326.3 & $27.3 \%$ & 27360 \\
\hline
\end{tabular}

of Tol (2005), as discussed in Sect. 3.3, and due to our assumption of a relatively moderate discount rate. A major part of the global abatement effort is carried out by the two regions that have very flat marginal abatement cost curves, the USA and China. For these regions, equating marginal abatement costs to marginal benefits implies substantial abatement levels. In contrast, Brazil, which is characterised by a very steep marginal abatement cost curve and low marginal benefits, hardly undertakes any abatement alone.

The relationship between the samples of global marginal benefits $\gamma$ and the corresponding global abatement levels is illustrated in Fig. 1 for the All-Singletons Coalition Structure. For samples with negative marginal benefits, optimal global abatement is zero. For positive marginal benefits, there is a clear positive correlation between the marginal benefits and global abatement, but the relation is not linear. As marginal abatement costs increase quadratic in abatement, higher marginal benefits lead to a less than proportional increase in abatement levels.

The graph clearly shows the dispersion of global marginal benefits as generated by the distribution function and the resulting dispersion of optimal global abatement levels. The bulk of samples produces global marginal benefits between 0 and $200 \$ / \mathrm{tC}$, with corresponding optimal global abatement of less than $200 \mathrm{GtC}$ over the century, though outliers may have marginal benefits of more than $800 \$ / \mathrm{tC}$, while global abatement may be as high as $400 \mathrm{GtC}$.

The Grand Coalition would lead to a much larger global abatement effort and a higher global payoff than no cooperation, as the gains from cooperation are fully reaped. However, the Grand Coalition has a low SL. Though it is externally stable by definition, the SL for internal stability is very low. In fact, the Grand Coalition is only stable when there are no benefits to be reaped from abatement, i.e. when the global benefit parameter $\gamma$ is zero or negative. In such cases, optimal abatement levels are zero, and hence regions have no incentive to leave this coalition. In the calculation of SL, this is interpreted as stable. Therefore, Table 4 also reports "Strict SL", which equals SL minus the "probability of indifference".

Only a few non-trivial coalitions (i.e. coalitions with at least two members) have a positive strict SL. All these coalitions are small and improve only little over the All-Singletons Coalition Structure. The coalition of Japan and the European Union (EEC) has the highest SL. 


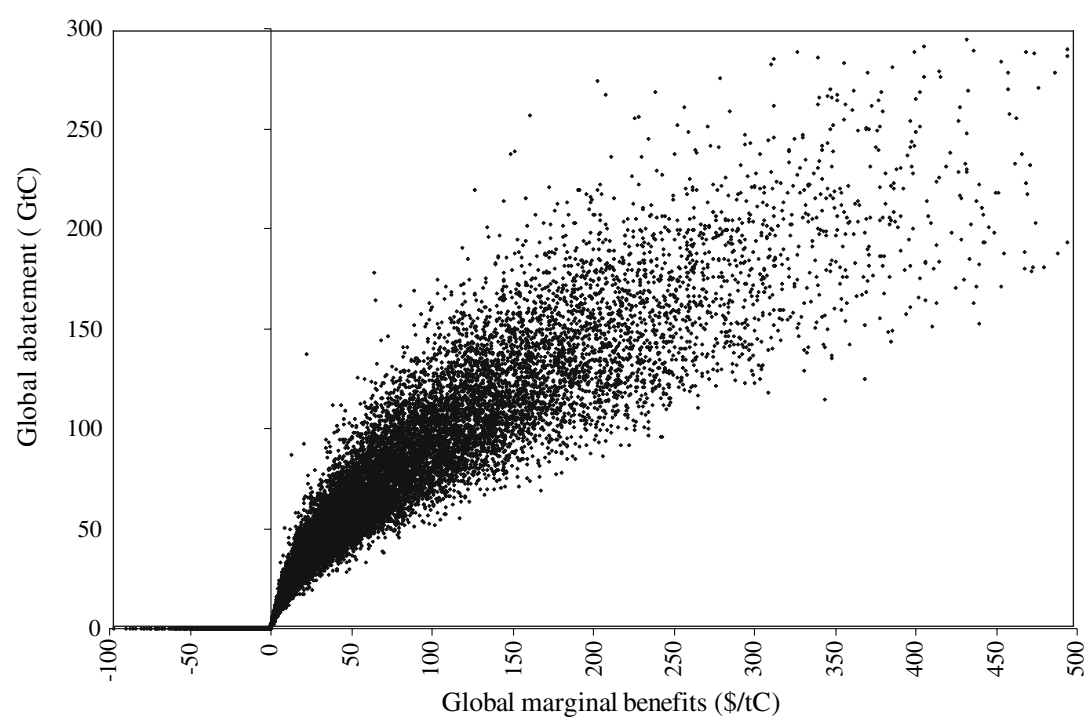

Fig. 1 Relationship between global marginal benefits and global abatement levels in the All-singletons coalition structure

Therefore, we have a closer look at this coalition in Table 5, which provides regional data. Though the standard deviations of the abatement levels are rather high, there is a probability of more than $90 \%$ that abatement levels are strictly positive, implying that the implicit distribution function for abatement levels is right-skewed. Though they are not part of the coalition, the largest abatement efforts are carried out by China and the USA. These regions have strong incentives to unilaterally reduce their emissions because of flat marginal abatement cost functions compared to their high constant marginal benefits. ${ }^{8}$ For Japan and the European Union, marginal abatement costs are equal to the sum of marginal benefits of this coalition, reflecting the first order condition implied by the assumption of joint welfare maximisation of coalitions as explained in Section $2 .^{9}$

The last column in Table 5 shows the mean incentive to change membership. For example, if the USA were to join the coalition of Japan and European Union, its mean payoff would be reduced by 247 bln $\$$. Similarly, Japan and the European Union would have a lower payoff of 79 and $12 \mathrm{bln} \$$, respectively, if they were to leave the coalition. It turns out that the mean values for the incentive to change membership are negative for all regions. Thus, a deterministic model assuming mean parameter values, would come to the conclusion that this coalition is stable. However, the corresponding SL is only $24 \%$, implying that in three quarter of all samples the coalition is unstable. This clearly illustrates the importance of using a more sophisticated stability indicator, such as SL, when the probability density functions of the model parameters are strongly skewed. Moreover, in a deterministic setting, no other coalition would be stable, even though there are some other coalitions with a positive SL.

\footnotetext{
8 This is in line with the arguments put forward by the Bush administration: the USA will not ratify the Kyoto protocol, but will carry out abatement efforts in its own interest.

${ }^{9}$ For singletons, the equality between regional marginal abatement costs and regional marginal benefits holds for every sample if marginal benefits are non-negative. However, this must not necessarily hold for mean values. Similarly, for coalition members regional marginal abatement costs equal the sum of marginal benefits of coalition members at the level of individual samples, but not necessarily for mean values.
} 
Table 5 Regional results of the coalition Japan (JPN) and the European Union (EEC)

\begin{tabular}{|c|c|c|c|c|c|c|c|c|}
\hline \multirow[t]{2}{*}{ Region } & \multicolumn{2}{|c|}{$\begin{array}{l}\text { Total abatement } \\
(\mathrm{GtC})\end{array}$} & \multirow{2}{*}{$\begin{array}{l}\text { Abatement } \\
\text { (\% emission) } \\
\text { Mean }\end{array}$} & \multicolumn{2}{|c|}{$\begin{array}{l}\text { Total payoff } \\
\text { (bln \$) }\end{array}$} & \multirow{2}{*}{$\begin{array}{l}\text { MAC }_{i}(\$ / \mathrm{tC}) \\
\text { Mean }\end{array}$} & \multirow{2}{*}{$\begin{array}{l}\mathrm{MB}_{i}(\$ / \mathrm{tC}) \\
\text { Mean }\end{array}$} & \multirow{2}{*}{$\begin{array}{l}\text { Incentive } \\
\text { (bln \$) } \\
\text { Mean }\end{array}$} \\
\hline & Mean & $\begin{array}{l}\text { Standard } \\
\text { deviation }\end{array}$ & & Mean & $\begin{array}{l}\text { Standard } \\
\text { deviation }\end{array}$ & & & \\
\hline USA & 20.31 & 16.01 & $8.4 \%$ & 2050 & 4313 & 17.6 & 17.3 & -247 \\
\hline JPN & 2.83 & 2.68 & $5.1 \%$ & 1650 & 3525 & 31.7 & 13.3 & -79 \\
\hline EEC & 12.29 & 9.15 & $8.8 \%$ & 2043 & 4213 & 31.7 & 17.9 & -12 \\
\hline OOE & 2.30 & 1.71 & $3.7 \%$ & 369 & 817 & 2.9 & 2.8 & -127 \\
\hline EET & 1.14 & 1.20 & $2.2 \%$ & 141 & 406 & 1.1 & 1.1 & -145 \\
\hline FSU & 5.64 & 5.11 & $5.6 \%$ & 670 & 1712 & 5.4 & 5.3 & -221 \\
\hline EEX & 1.40 & 2.01 & $1.2 \%$ & 312 & 850 & 2.5 & 2.4 & -206 \\
\hline $\mathrm{CHN}$ & 21.02 & 24.19 & $8.9 \%$ & 611 & 1739 & 4.9 & 4.8 & -1282 \\
\hline IND & 3.30 & 5.59 & $5.2 \%$ & 441 & 1647 & 3.6 & 3.5 & -289 \\
\hline DAE & 0.81 & 1.80 & $2.0 \%$ & 245 & 1008 & 1.9 & 1.9 & -167 \\
\hline BRA & 0.03 & 0.08 & $0.2 \%$ & 151 & 636 & 1.2 & 1.2 & -11 \\
\hline ROW & 3.42 & 5.54 & $4.9 \%$ & 568 & 2117 & 4.7 & 4.6 & -227 \\
\hline
\end{tabular}

Note: $\mathrm{MAC}_{i}=$ regional marginal abatement costs; $\mathrm{MB}_{i}=$ regional marginal benefits, Incentive $=$ change in net benefits if one region changes its announcement of membership, given the announcement of all other regions where initially all regions anncounce $c_{i}=0$, except JPN and EEC that announce $c_{i}=1$

As discussed in the introduction, we can also relate our results to the cases of no and full learning in the presence of uncertainty (i.e. no and full resolution of uncertainty) as described in Kolstad and Ulph (2006). The case of no learning corresponds to the deterministic setting. Hence, the expected total payoff in case of no learning is $9251 \mathrm{bln} \$$, resulting from the only stable coalition between Japan and the European Union. In the case of full learning, the expected payoff is the average payoff of all stable coalitions for each parameter sample. It seems plausible to assume that if there are multiple stable coalitions for a sample, each equilibrium is equally likely. It turns out that expected payoff is $9105 \mathrm{bln} \$$. Hence, the impact of learning on the global payoff is negative in this example, confirming the conclusion of Kolstad and Ulph (2006).

\subsection{Ranking the uncertainties}

Based on the information on individual samples, we can investigate which uncertainties are significant in influencing the stability of a coalition. Unfortunately, we cannot derive a ranking of the uncertainties directly from the SL estimator. The fact that not all stochastic parameters are normally distributed requires that we have to resort to numerical approximations. Using a meta-modelling approach, we construct a Probit model to identify which of the uncertain parameters influence the stability of the coalition between Japan and the European Union. To allow for a direct interpretation of the coefficients, we standardise all inputs such that they lie in the interval $[0,1]$. The results are depicted in Table 6.

The main determinant of stability of the coalition is the level of global benefits: higher benefit levels have a negative impact on the stability of this coalition. As expected, there is a positive impact of the benefit share of the coalition member European Union (EEC), while the benefit shares of other regions mostly have a negative or insignificant impact on stability. 
Table 6 Results of the meta-analysis of the coalition between Japan and the European Union

\begin{tabular}{|c|c|c|c|c|c|}
\hline Parameter & Coefficient & Standard deviation & Parameter & Coefficient & Standard deviation \\
\hline Global benefits & -3.64 & $0.10 * *$ & Intercept & -0.15 & 0.11 \\
\hline \multicolumn{3}{|c|}{ Benefit shares } & \multicolumn{3}{|c|}{ Abatement cost parameter } \\
\hline USA & -1.50 & $0.08 * *$ & USA & -0.10 & 0.06 \\
\hline JPN & 0.03 & 0.07 & JPN & -0.05 & 0.06 \\
\hline EEC & 2.54 & $0.06 * *$ & EEC & 0.12 & $0.06 * *$ \\
\hline OOE & -0.01 & 0.07 & OOE & -0.00 & 0.06 \\
\hline EET & -0.04 & 0.09 & EET & 0.00 & 0.06 \\
\hline FSU & -0.49 & $0.09 * *$ & FSU & -0.08 & 0.06 \\
\hline EEX & 0.01 & 0.09 & EEX & 0.07 & 0.06 \\
\hline $\mathrm{CHN}$ & -0.04 & 0.08 & $\mathrm{CHN}$ & 0.05 & 0.07 \\
\hline IND & -1.50 & $0.16^{* *}$ & IND & 0.05 & 0.06 \\
\hline DAE & -0.72 & $0.10 * *$ & DAE & 0.08 & 0.06 \\
\hline BRA & -2.37 & $0.16 * *$ & BRA & -0.10 & 0.06 \\
\hline ROW & -1.94 & $0.14 * *$ & ROW & -0.05 & 0.06 \\
\hline
\end{tabular}

Note: ** indicates significance at the $5 \%$ level; pseudo $R^{2}$ equals 0.09

Surprisingly, the benefit share of Japan is also insignificant. This means that Japan has a large incentive to collaborate, even when its regional benefit level turns out to be relatively low. This can be explained by noting that Japan has to contribute little to cooperation because of its steep marginal abatement cost function. The large coefficient of the benefit share of the European Union confirms the importance of internal stability. The significant and negative coefficients of the benefit shares of the USA, former Soviet Union, India, dynamic Asian economies, Brazil and the Rest of the World indicate that when these regions have high benefit shares, they will want to join the coalition of Japan and the European Union, thereby making it externally unstable.

Table 6 confirms that marginal abatement costs are much less important; this is related to the assumed smaller variance of the marginal abatement cost parameters (see Sect. 3 ). The only significant parameter for abatement costs is that of the European Union. As the positive coefficient shows, higher marginal abatement costs in the European Union have a positive impact on stability of the coalition with Japan. The reason is the same as mentioned for Japan above. A steep marginal abatement cost curve implies for a coalition member a small share in coalitional abatement efforts and hence a lower incentive to free-ride.

A similar probit analysis is carried out for the coalition between the USA and Japan; the results are depicted in Table 7.

The significant inputs for the stability of this coalition are the same as for the coalition between Japan and the European Union; additionally the benefit shares of Japan (negative effect) and Other OECD (positive effect) are important. The ranking of the main uncertainties is also the same, except for the higher ranking of the benefit share of the USA. As the USA is now a coalition member and the European Union is not, the signs of their benefit coefficients reverse. The high ranking of the European Union (3rd) shows that external stability can pose a problem in some cases: a high marginal benefit share in the European Union induces this region to join the coalition of the USA and Japan, thereby making it externally unstable. Though the benefit share of Japan is significant in explaining the SL of the coalition between 
Table 7 Results of the meta-analysis of the coalition between the USA and Japan

\begin{tabular}{|c|c|c|c|c|c|}
\hline Parameter & Coefficient & Standard deviation & Parameter & Coefficient & Standard deviation \\
\hline Global benefits & -8.24 & $0.16 * *$ & Intercept & 0.26 & 0.13 \\
\hline \multicolumn{3}{|c|}{ Benefit shares } & \multicolumn{3}{|c|}{ Abatement cost parameter } \\
\hline USA & 3.08 & $0.08 * *$ & USA & 0.09 & 0.07 \\
\hline JPN & -0.36 & $0.09 * *$ & JPN & -0.09 & 0.07 \\
\hline EEC & -1.95 & $0.09 * *$ & EEC & -0.12 & 0.07 \\
\hline OOE & 0.17 & $0.08 * *$ & OOE & -0.02 & 0.07 \\
\hline EET & 0.04 & 0.11 & EET & 0.10 & 0.07 \\
\hline FSU & -0.60 & $0.10 * *$ & FSU & -0.08 & 0.07 \\
\hline EEX & -0.05 & 0.10 & EEX & -0.05 & 0.07 \\
\hline $\mathrm{CHN}$ & 0.01 & 0.09 & $\mathrm{CHN}$ & -0.08 & 0.08 \\
\hline IND & -1.18 & $0.19 * *$ & IND & 0.07 & 0.07 \\
\hline DAE & -0.47 & $0.11^{* *}$ & DAE & 0.07 & 0.07 \\
\hline BRA & -1.65 & $0.18 * *$ & BRA & -0.06 & 0.07 \\
\hline ROW & -1.32 & $0.16 * *$ & ROW & -0.06 & 0.13 \\
\hline
\end{tabular}

Note: ** indicates significance at the $5 \%$ level; pseudo $R^{2}$ equals 0.17

the USA and Japan, its ranking is rather low, confirming the finding above that the incentive for Japan to leave the coalition is in most circumstances (strongly) negative and thus cannot explain the variation in stability.

\subsection{Results for the alternative specification with lower mean global benefits}

We expect that the probability density function of the global benefit parameter $\gamma$ is crucial for the analysis. Moreover, estimates of future benefits from abatement are widely acknowledged to be highly uncertain. Therefore, we carry out an alternative simulation with a different assumption on the global benefit parameter $\gamma$. Table 8 shows results assuming that the 5 percentile point is set to $0 \$ / \mathrm{tC}$ and the 95 percentile point is set to $110 \$ / \mathrm{tC}$. This implies that extreme values are rare and that the mean value of the global benefit parameter $\gamma$ is reduced from 77 to $37 \$ / \mathrm{tC}$. Note that in the STACO model, a lower mean value of $\gamma$ has a similar impact as raising the discount rate as explained in Weikard et al. (2006) : as benefits from abatement will occur later than the associated costs, a higher discount rate implies a smaller weight of (future) benefits and vice versa; see also the discussion of equation [4a]. Thus, the discount rate is not explicitly subjected to a sensitivity analysis, but only implicitly. The specific values considered here correspond to raising the discount rate from 2 to 7 percent. ${ }^{10}$

For all coalitions, the SL is lower than in the base specification. This is partly due to the lower probability of negative marginal benefits (this probability is reduced to 5\%) and partly due to the fact that mostly positive outliers of marginal benefits are removed from the model. The ranking (in terms of SL) of different coalitions is largely unchanged, implying that only the quantitative but not the qualitative conclusions are affected.

The lower mean value of $\gamma$ reduces equilibrium abatement. In the All-Singletons Coalition Structure, global abatement drops from around $70 \mathrm{GtC}$ per century to $45 \mathrm{GtC}$. The reduction

10 Analogous to the procedure explained in note 5, we can also mimic these results using the Ramsey rule; the associated pure rate of time preference equals $5.2 \%$. 
Table 8 Results for selected coalitions assuming smaller bounds on the global benefit parameter $\gamma$

\begin{tabular}{lllll}
\hline Coalition & SL (fraction) & $\begin{array}{l}\text { Strict SL } \\
\text { (fraction) }\end{array}$ & $\begin{array}{l}\text { Mean total } \\
\text { abatement } \\
(\mathrm{GtC})\end{array}$ & $\begin{array}{l}\text { Mean total } \\
\text { payoff } \\
\text { (bln \$) }\end{array}$ \\
\hline All-Singletons & 1 & 1 & 44.5 & 2520 \\
JPN,EEC & 0.20 & 0.15 & 47.9 & 2660 \\
USA,JPN & 0.11 & 0.06 & 51.2 & 2790 \\
USA,EEC & 0.10 & 0.05 & 55.2 & 2929 \\
JPN,BRA & 0.07 & 0.02 & 44.7 & 2532 \\
JPN,ROW & 0.07 & 0.02 & 49.5 & 2774 \\
EEC,ROW & 0.06 & 0.01 & 51.2 & 2844 \\
JPN,IND & 0.06 & 0.01 & 50.3 & 2819 \\
EEC,BRA & 0.06 & 0.01 & 45.0 & 2543 \\
JPN,FSU & 0.06 & 0.01 & 49.1 & 2738 \\
EEC,IND & 0.06 & 0.01 & 52.1 & 2894 \\
Grand Coalition & 0.05 & 0.00 & 225.8 & 8353 \\
\hline
\end{tabular}

in mean marginal benefits does not translate into a proportional reduction in mean abatement levels. This is due to the non-linear nature of the model: the quadratic marginal abatement cost functions imply that lower constant marginal benefits lead to less than proportionately lower abatement levels ( $c f$. Fig. 1). Lower benefits and abatement levels also lead to lower payoffs ( 2.5 trillion $\$$ versus 8.8 trillion $\$$ ) compared to the base specification.

It is interesting to note that in a deterministic setting, with $\gamma=37 \$ / \mathrm{tC}$, no coalition except the All-Singletons Coalition Structure would be stable. Only if this value is raised by more than $20 \%$ does the coalition between Japan and the European Union emerge as stable coalition. In contrast, the SL-value changes only from $20 \%$ to $24 \%$ if the mean value of $\gamma$ is raised from 37 to $77 \$ / \mathrm{tC}$. Once more, this highlights that the SL-concept is useful when conducting an analysis of stability of coalitions when parameter values are not exactly known. Again, we can relate our results to the cases of no and full learning in Kolstad and Ulph (2006). In the case of no learning, the expected total payoff is $2520 \mathrm{bln} \$$, resulting from the All-Singleton Coalition Structure. For the expected payoff in the case of learning we find, according to the procedure outlined in Sect. 4.1, a value of 2724 bln \$. Thus, now learning has a positive impact on the global payoff, in contrast with the finding in Kolstad and Ulph (2006). However, it has to be pointed out that Kolstad and Ulph's assumptions imply that in the case of no learning at least a coalition of two countries is stable. Hence, our different conclusion may rely exactly on this fact.

\subsection{Results of the sensitivity analyses}

In order to shed light on the robustness of our previous conclusions, a series of sensitivity analyses are carried out. The main results of alternative assumptions regarding the uncertainty of the main model parameters are reported in Table 9. A second set of sensitivity analyses, which is reported in Table 10, concerns the functional forms of the distribution of uncertain parameters.

A general conclusion that emerges from Tables 9 and 10 is that although the regional abatement levels and payoffs depend on several model parameters, the sensitivity of SL is 
Table 9 Stability Likelihood of selected coalitions under different model specifications

\begin{tabular}{lllll}
\hline Coalition & $\begin{array}{l}\text { Base } \\
\text { specification }\end{array}$ & $\begin{array}{l}\text { No uncertainty } \\
\text { w.r.t. } s_{i}\end{array}$ & $\begin{array}{l}\text { No uncertainty } \\
\text { w.r.t. } \gamma\end{array}$ & $\begin{array}{l}\text { No uncertainty } \\
\text { w.r.t. } \alpha_{i}, \beta_{i}\end{array}$ \\
\hline JPN,EEC & 0.24 & 0.63 & 0.17 & 0.24 \\
USA,JPN & 0.15 & 0.09 & 0.07 & 0.15 \\
USA,EEC & 0.14 & 0.09 & 0.06 & 0.14 \\
JPN,BRA & 0.12 & 0.09 & 0.02 & 0.11 \\
JPN,ROW & 0.11 & 0.09 & 0.02 & 0.11 \\
EEC,ROW & 0.11 & 0.09 & 0.02 & 0.10 \\
JPN,IND & 0.10 & 0.09 & 0.01 & 0.10 \\
JPN,FSU & 0.10 & 0.09 & 0.01 & 0.10 \\
EEC,BRA & 0.10 & 0.09 & 0.01 & 0.10 \\
EEC,FSU & 0.10 & 0.09 & 0.01 & 0.10 \\
Grand Coalition & 0.09 & 0.09 & 0 & 0.09 \\
\hline
\end{tabular}

Table 10 Stability Likelihood of selected coalitions under different model specifications

\begin{tabular}{llllll}
\hline Coalition & Base specification & Normal distribution $s_{i}$ & $\begin{array}{l}\text { Normal } \\
\text { distribution } \\
\gamma\end{array}$ & $\begin{array}{l}\text { Gamma } \\
\text { distribution } \\
\alpha_{i}, \beta_{i}\end{array}$ & $\begin{array}{l}\sum_{\text {varies }} \\
\text { from unity }\end{array}$ \\
\hline JPN,EEC & 0.24 & 0.26 & 0.32 & 0.24 & 0.24 \\
USA,JPN & 0.15 & 0.13 & 0.24 & 0.15 & 0.15 \\
USA,EEC & 0.14 & 0.14 & 0.23 & 0.14 & 0.14 \\
JPN,BRA & 0.12 & 0.09 & 0.20 & 0.11 & 0.11 \\
JPN,ROW & 0.11 & 0.09 & 0.20 & 0.11 & 0.11 \\
EEC,ROW & 0.11 & 0.09 & 0.20 & 0.10 & 0.11 \\
JPN,IND & 0.10 & 0.06 & 0.20 & 0.10 & 0.10 \\
JPN,FSU & 0.10 & 0.07 & 0.20 & 0.10 & 0.10 \\
EEC,BRA & 0.10 & 0.08 & 0.19 & 0.10 & 0.10 \\
EEC,FSU & 0.10 & 0.08 & 0.19 & 0.10 & 0.10 \\
Grand Coalition & 0.09 & 0.01 & 0.19 & 0.09 & 0.09 \\
\hline
\end{tabular}

much smaller. Essentially, the value of SL depends crucially on two elements: (i) the variance in regional benefit shares $\left(s_{i}\right)$, and (ii) the variance and level of the global benefit parameter $(\gamma)$. Reducing the uncertainty with respect to the regional benefit shares from the model greatly reduces the variability of stability over the different coalitions. Thus, when regional benefit shares are known, it becomes much easier to predict which regions have incentives to collaborate and which do not. Then, only the coalition between Japan and the European Union has a SL that is significantly higher than the probability of indifference. Removing the uncertainty in the global benefit parameter implies that the probability of indifference is zero, and this affects the SL of all coalitions.

The ranking of different coalitions in terms of their SL is very robust: in all simulations, the same ranking emerges; the coalition between Japan and the European Union has the highest SL, followed by the coalition between the USA and Japan and the coalition between 
the USA and the European Union. Thus, we can conclude that SL provides a highly robust indicator of the stability of climate coalitions.

This is also confirmed in the last column in Table 10 where the assumption is given up that the sum of regional benefit shares is one. Thus, global benefit levels vary not only with the variations in the global benefit parameter, but also with the sum of the regional shares. It turns out that this assumption was not important: results are very similar to the base specification.

\section{Discussion}

This paper investigated the formation and stability of coalitions to reduce the negative impacts of climate change. We introduced a methodology to calculate the stability of all possible coalition structures in a stochastic, empirical setting. The concept of SL provided a notion of stability that conveyed much more relevant information than the ordinary binary outcome: stable/unstable. The numerical application showed that the SL-concept contributes to a better understanding of stability of coalitions when there is uncertainty about model parameters: it constitutes a superior alternative to running numerous sensitivity analyses in a deterministic setting.

The results suggested that for most possible climate coalition there is at least one region that is better off by changing its actions, thereby rendering coalitions unstable. This included important coalitions such as the coalition of industrialised countries and the Grand Coalition. The lack of stability was very robust and held for a wide range of possible values for regional abatement costs and benefits, as described by the respective probability distribution functions. There were only a small number of coalitions with a (strict) SL significantly different from zero. Only when benefits from abatement are zero or negative (calibrated to be around 9 percent in the base specification), i.e. when climate change does not pose a problem, will regions be indifferent between cooperation and no cooperation. However, in such cases, the optimal abatement levels were zero, regardless of which coalitions formed.

The coalition with the highest SL was the coalition of Japan and the European Union, with an SL equal to $24 \%$ in our base case. This relatively low percentage stressed the difficulties in striking an international environmental agreement. This coalition but also the other coalitions with a positive SL hardly improved over the All-Singletons Coalition Structure, corresponding to the case of no cooperation: global abatement and global welfare were only slightly higher than when there was no international collaboration at all, confirming a conclusion in the literature derived with deterministic models.

The calculated SL of different coalitions was robust in terms of the considered distribution functions of parameter values, the variance in regional abatement costs and the global level of benefits from global abatement, but was sensitive to the variance in the regional distribution of benefits. Unfortunately, regional benefits from abatement are very uncertain, and international research on adaptation and damage costs is still in its infancy. Therefore, it is of utmost importance to get better information on regional benefits.

We also related our results to those derived from stylized models with ex-ante symmetric players which conclude that learning has a negative impact on the outcome of coalition formation. It became apparent that our approach corresponds to the case of full resolution of uncorrelated uncertainty with perfect learning, according to the classification in Kolstad and Ulph (2006). This case could be compared to the case of no resolution of uncertainty where decisions on coalition membership have to be taken on the basis of expected values. We showed that learning may not always have a negative impact on global welfare. This suggested that the conclusions derived from stylized models as for instance in 
Na and Shin (1998), Kolstad and Ulph (2006) and Kolstad (2007) are sensitive to the underlying assumptions.

There are many ways in which the analysis above can be ameliorated. Firstly, better estimates of the variance on regional benefits may be obtained via a meta-analysis of the existing literature, similar to what Tol (2005) did for global benefits. Secondly, the empirical model used to calculate the regional payoffs can be extended to a fully-fledged computable general equilibrium model. Together, we expect that these two extensions will improve the empirical validity of the numerical example. Thirdly, it would be interesting to consider the case of partial learning as analysed in Kolstad and Ulph (2006) in order to better understand the role of learning. Finally, the analysis could be extended to decision making under uncertainty by including risk-aversion of players as for instance considered in Endres and Ohl (2003).

\section{Appendix 1. Histograms of the uncertain model parameters}

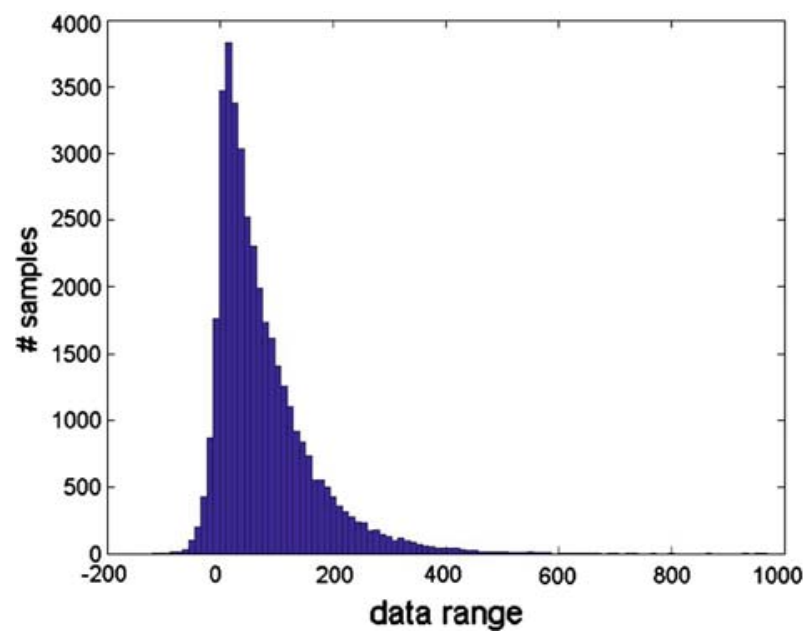

Fig. A.1 Histogram of the global benefit parameter $(\gamma)$
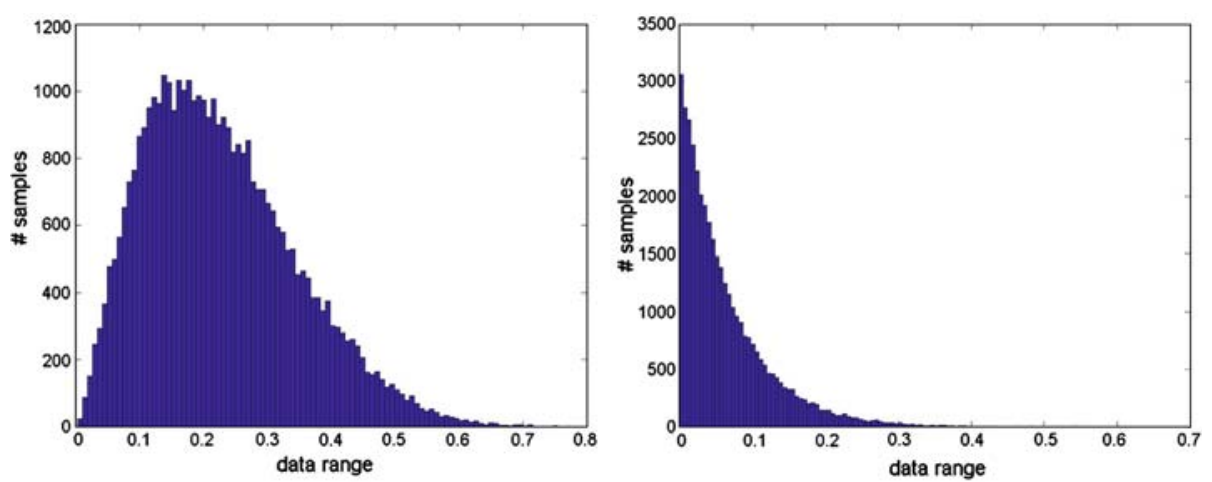

Fig. A.2 Histogram of the regional benefit parameters $\left(s_{i}\right)$ for USA and China, respectively 

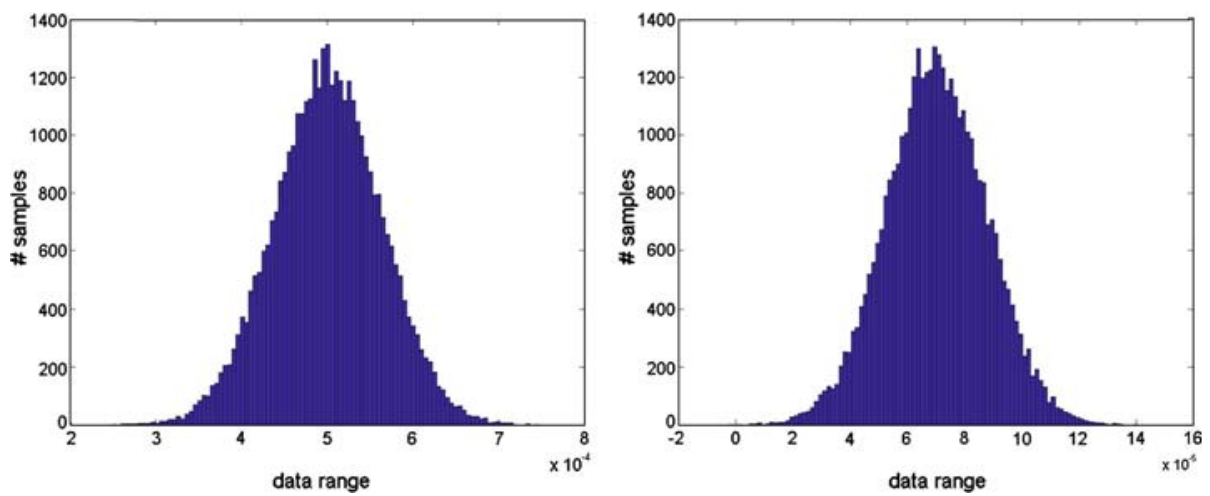

Fig. A.3 Histogram of the regional abatement cost parameter $\left(\alpha_{i}\right)$ for USA and China, respectively

Acknowledgements Special thanks to Ivo Mulder and Kelly de Bruin for their research assistance and to Ekko van Ierland, Eligius Hendrix, John Janmaat and two anonymous referees for their comments; the usual disclaimer applies.

\section{References}

Babiker MH, Reilly JM, Mayer M, Eckaus RS, SueWing I, Hyman RC (2001) The MIT emissions prediction and policy analysis (EPPA) model: revisions, sensitivities and comparison of results. Joint program on the science and policy of global change Report, 71. MIT, Cambridge

Barrett S (1994) Self-enforcing international environmental agreements. Oxford Economic Papers 46:878-894

Bosello F, Buchner B, Carraro C (2003) Equity, development, and climate change control. J Euro Econ Assoc 1:601-611

Botteon M, Carraro C(1997) Burden-sharing and coalition stability in environmental negotiations with asymmetric countries. In: Carraro $\mathrm{C}$ (ed) International environmental negotiations: strategic policy issues. Edward Elgar, Cheltenham 26-55

Carraro C, Siniscalco D (1993) Strategies for the iternational potection of the environment. J Publ Econ 52:309_ 328

Dellink RB, Finus M, van Ierland EC, Altamirano J-C (2004) Empirical background paper of the STACO model, available on the STACO website http://www.enr.wur.nl/uk/staco, Wageningen University

Ellerman AD, Decaux A (1998) Analysis of post-Kyoto $\mathrm{CO}_{2}$ emissions trading using marginal abatement curves. Joint program on the science and policy of global change Report, vol 40. MIT, Cambridge

Endres A, Ohl C (2003) International environmental cooperation with risk aversion. Int J Sustain Develop 6:378-392

Eyckmans J, Finus M(2006)Coalition formation in a global warming game: how the design of protocols affects the success of environmental treaty-making. Nat Resour Model 19:323-358

Fankhauser S (1995) Valuing climate change. Earthscan, London

Finus M, van Ierland EC, Dellink RB (2006) Stability of climate coalitions in a cartel formation game. Econ Govern 7:271-291

Hoel M(1992) International environment conventions: the case of uniform reductions of emissions. Environ Resour Econ 2:141-159

Kolstad CD (1996) Fundamental irreversibilities in stock externalities. J Publ Econ 60:221-233

Kolstad CD (1996) Learning and stock effects in environmental regulation: the case of greenhouse gas emissions. J Environ Econ Manage 31:1-18

Kolstad CD (2007) Systematic uncertainty in self-enforcing international environmental agreements. J Environ Econ Manage 53:68-79

Kolstad CD, Ulph A (2006) International environmental agreements under uncertainty when learning reveals differences between countries, paper presented at the conference "Learning and climate change". IIASA, Laxenburg, Austria 
Manne AS, Mendelsohn R, Richels RG(1995) Merge:a model for evaluating regional and global effects of GHG reduction policies. Energy Policy 23:17-34

Metz B, Davidson O, Swart R, Pan J (eds) (2001) Climate change 2001: mitigation. Cambridge University Press, Cambridge

Na S, Shin HS (1998) International environmental agreements under uncertainty. Oxford Economic Papers 50:173-185

Nagashima M, Dellink RB, van Ierland EC(2006) Dynamic transfer schemes and stability of international climate coalitions. Mansholt Discussion Paper 23, Wageningen

Nordhaus WD(1994) Managing the global commons. MIT Press, Cambridge

Nordhaus WD, Boyer J(2000) Warming the world: economic models of global warming. MIT Press, Cambridge

Olieman NJ, Hendrix EMT(2006) Stability likelihood of coalitions in a two-stage cartelgame: an estimation method. Euro J Oper Res 174:333-348

Roughgarden T, Schneider SH(1999) Climate change policy: quantifying uncertainties for damages and optimal carbon taxes. Energy Policy 27:415-429

Tol RSJ (1997) A decision-analytic treatise of the enhanced greenhouse effect. PhD. Thesis. Vrije Universiteit, Amsterdam

Tol RSJ (2001) Climate coalitions in an integrated assessment model. Computat Econ 18:159-172

Tol RSJ (2002) Estimates of the damage costs of climate change: part 1: benchmark estimates. Environ Resour Econ 21:47-73

Tol RSJ (2005) The marginal damage costs of carbon dioxide emissions: an assessment of the uncertainties. Energy Policy 33:2064-2074

Ulph A (2004) Stable international environmental agreements with a stock pollutant, uncertainty and learning. J Risk Uncertain 29:53-73

Ulph A, Maddison D (1997) Uncertainty, learning and international environmental policy coordination. Environ Resour Econ 9:451-466

Ulph A, Ulph D(1997) Global warming, irreversibility and learning. Econ J 107:636-650

Weikard H-P, Finus M, Altamirano-Cabrera JC (2006) The impact of surplus sharing on the stability of international climate coalitions. Oxford Econ Papers 58:209-232

Weitzman ML(1998) Why the far-distant future should be discounted at its lowest possible rate. J Environ Econ Manage 36:201-208

Weitzman ML(2001) Gamma discounting. Am Econ Rev 91:260-71 